\title{
Non-invasive mechanical ventilation after the successful weaning: a comparison with the venturi mask
}

\author{
Esra Adıyeke, Asu Ozgultekin, Guldem Turan*, Altay Iskender, Gamze Canpolat, \\ Abdullah Pektaș, Osman Ekinci
}

Haydarpasa Numune Teaching and Research Hospital, Department of ICU, Istanbul, Turkey

Received 6 April 2014; accepted 11 November 2014

Available online 20 October 2015

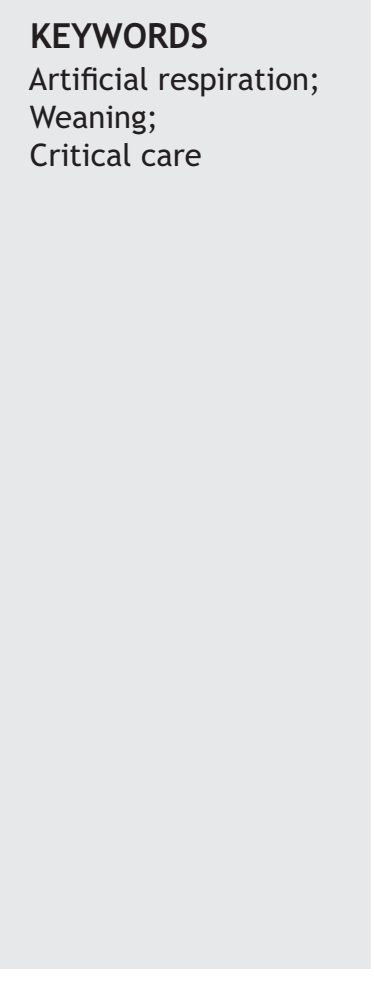

\begin{abstract}
Background and objectives: This study compared the rates of acute respiratory failure, reintubation, length of intensive care stay and mortality in patients in whom the non-invasive mechanical ventilation (NIMV) was applied instead of the routine venturi face mask (VM) application after a successful weaning.

Methods: Following the approval of the hospital ethics committee, 62 patients who were under mechanical ventilation for at least 48 hours were scheduled for this study. 12 patients were excluded because of the weaning failure during T-tube trial. The patients who had optimum weaning criteria after the T-tube trial of 30 minutes were extubated. The patients were kept on VM for 1 hour to observe the hemodynamic and respiratory stability. The group of 50 patients who were successful to wean randomly allocated to have either VM $(n=25)$, or NIV $(n=25)$. Systolic arterial pressure (SAP), heart rate $(\mathrm{HR})$, respiratory rate $(\mathrm{RR}), \mathrm{PaO}_{2}, \mathrm{PCO}_{2}$, and $\mathrm{pH}$ values were recorded.

Results: The number of patients who developed respiratory failure in the NIV group was significantly less than VM group of patients ( 3 reintubation vs. 14 NIV +5 reintubation in the VM group). The length of stay in the ICU was also significantly shorter in NIV group (5.2 \pm 4.9 vs. $16.7 \pm 7.7$ days).

Conclusions: The ratio of the respiratory failure and the length of stay in the ICU were lower when non-invasive mechanical ventilation was used after extubation even if the patient is regarded as 'successfully weaned'. We recommend the use of NIMV in such patients to avoid unexpected ventilator failure.

(C) 2015 Sociedade Brasileira de Anestesiologia. Published by Elsevier Editora Ltda. This is an open access article under the CC BY-NC-ND license (http://creativecommons.org/licenses/bync-nd/4.0/).
\end{abstract}

\footnotetext{
* Corresponding author.

E-mail: gturanmd@yahoo.com (G. Turan).
} 


\section{PALAVRAS-CHAVE \\ Respiração artificial; Desmame; \\ Cuidados intensivos}

\author{
Ventilação mecânica não invasiva após desmame bem-sucedido: uma comparação \\ com a máscara de Venturi
}

\begin{abstract}
Resumo
Justificativa e objetivos: Este estudo comparou as taxas de insuficiência respiratória aguda, reintubação, tempo de internação em UTI e mortalidade em pacientes sob ventilação mecânica não invasiva (VMNI) em vez da habitual máscara facial de Venturi (MV) após desmame bemsucedido.

Métodos: Após a aprovação do Comitê de Ética do hospital, 62 pacientes que estavam sob ventilação mecânica por no mínimo 48 horas foram inscritos neste estudo. Doze pacientes foram excluídos devido à falha de desmame durante o teste de tubo-T. Os pacientes que apresentaram critérios de desmame ótimos após o teste de tubo-T de 30 minutos foram extubados. Os pacientes foram mantidos em MV por 1 hora para observação da estabilidade hemodinâmica e respiratória. 0 grupo de 50 pacientes que obtiveram sucesso no desmame ventilatório foram alocados aleatoriamente para MV $(n=25)$ ou VNI $(n=25)$. Os valores de pressão arterial sistólica (PAS), frequência cardíaca ( $\mathrm{FC}$ ), frequência respiratória (FR), $\mathrm{PaO}_{2}, \mathrm{PCO}_{2}$ e pH foram registrados.

Resultados: O número de pacientes que desenvolveu insuficiência respiratória no grupo VNI foi significativamente menor que o do grupo MV (3reintubações vs. $14 \mathrm{VNI}+5$ reintubações no grupo MV). 0 tempo de permanência em UTI também foi significativamente menor no grupo NIV (5,2 $2 \pm 4,9$ vs. $16,7 \pm 7,7$ dias).

Conclusões: As taxas de insuficiência respiratória e do tempo de permanência em UTI foram menores quando a ventilação mecânica não invasiva foi usada após a extubação, mesmo se o paciente for considerado como "desmame bem-sucedido"'. Recomendamos o uso de VMNI em tais pacientes para evitar a falha inesperada do ventilador.

(c) 2015 Sociedade Brasileira de Anestesiologia. Publicado por Elsevier Editora Ltda. Este é um artigo Open Access sob uma licença CC BY-NC-ND (http://creativecommons.org/licenses/bync-nd/4.0/).
\end{abstract}

\section{Introduction}

Non-invasive ventilation takes a role in different stages of treatment in intensive care units. This method is commonly used as an alternative to invasive ventilation in patients who are clinically stable but suffer from acute hypercapnic respiratory failure. ${ }^{1-3}$ NIV is also used for premature weaning and post extubation respiratory failure and positive results on reintubation and duration of intensive care unit stay is reported. ${ }^{4}$

In this study, we aimed to determine if prophylactic NIV applied to the patients who were extubated according to the standardized weaning criteria and who were appropriate for following with venture face mask (VM) would make any difference in terms of respiratory failure after extubation, reintubation, duration of intensive care unit stay and mortality.

\section{Materials and methods}

Sixty-two patients above 18-years old who were admitted to intensive care unit with acute respiratory failure and treated with invasive mechanical ventilatory support for more than $48 \mathrm{~h}$ were included in the study. Patients whose APACHE II (Acute Physiology and Chronic Health Evaluation II) score above 25, GCS (Glasgow Coma Scale) below 13 and who have contraindications for NIV (patients with maxillofacial trauma, gastrointestinal obstruction and severe secretion), severe irreversible organ failure and pregnancy were excluded from the study. Demographic data, diagnosis, comorbidities, and APACHE II scores of the patients were recorded. Weaning was planned for the patients who have optimal conditions: CPAP mode with invasive mechanic ventilation support who have $\mathrm{FiO} \leq 40, \mathrm{PaO}_{2} \geq 60, \mathrm{PEEP} \leq 5$, $\mathrm{SO}_{2} \geq 90$ and not having inotrope support; systolic arterial pressure between 70 and $180 \mathrm{mmHg}$, peak heart rate between 50 and $140 \mathrm{~min}$, respiratory rate $<25 \mathrm{~min}, \mathrm{GCS} \geq 13$. Patients who fulfilled these criteria were taken under spontaneous respiratory trial with T-part for $30 \mathrm{~min}$. Arterial blood gas was evaluated after 30 min spontaneous respiratory trial. If hemodynamic and respiratory parameters were stable, patients were extubated and supported with $\mathrm{O}_{2}$ by VM. Patients were followed up for an hour to observe sufficiency in terms of weaning and the ones who had $\mathrm{SO}_{2} \geq 90$, systolic arterial pressure between 70 and $180 \mathrm{mmHg}$, peak heart rate between 50 and $140 \mathrm{~min}$, respiratory rate $<25 \mathrm{~min}$ were included in the study. The patients were chosen into the groups according to the admission number as having odd or even number.

At the end of the first hour, the patients who could not provide these parameters and impaired hemodynamics or respiratory pattern, were return to mechanical ventilation (IMV or NIV) and excluded from the study. While one of the groups (Group VM) were continued to have $\mathrm{O}_{2}$ support by VM from the first hour of extubation, the other group (Group NIV) were put on NIV from the first hour of extubation. The function of the NIV was explained to the patients in NIV 
group. Mechanical ventilation parameters of the patients supported by NIV were set as IPAP: $13-15 \mathrm{~cm} \mathrm{H}_{2} \mathrm{O}$ vs. EPAP: 3-5 $\mathrm{cm} \mathrm{H} \mathrm{H}_{2} \mathrm{O}$ according to patient compliance. Different types of NIV masks (full-face and oronasal-forehead or chin supported) were chosen for application in order to provide patient comfort and compliance. During the follow-up, low dose dexmedetomidine sedation $(0.2-0.5 \mathrm{mg} / \mathrm{kg} / \mathrm{h}$ infusion) was planned to be initiated if the patient's incompliance was preventing NIV to be effective.

Arterial pressure, pulse, respiratory rate and arterial blood gas parameters were recorded before extubation, under IMV in CPAP mode; in the 30th minute of T-piece trial; and after extubation in 1st, 2nd, 3rd, 4th, 5th, 6th, 12th, 24th, 48th hours in all patients. Complications (vomiting, airway obstruction, regurgitation, etc.) were recorded.

In Group VM, patients who did not have respiratory failure and intubation indication but developed respiratory deterioration and slight hypoxia (respiratory rate $>25 \mathrm{~min}, \mathrm{SO}_{2} \leq 95$, $\mathrm{PaO}_{2} \leq 70 \mathrm{mmHg}$ ) were supported with NIV; while patients in both groups who had respiratory failure and intubation indication (respiratory rate $>35 \mathrm{~min}, \mathrm{SO}_{2}<90, \mathrm{PaO}_{2}<60 \mathrm{mmHg}$ and hemodynamic failure) were reintubated.

Continuity of weaning success, respiratory failure after extubation, reintubation, duration of intensive care unit stay and mortality rates are compared between two groups.

During the evaluation of the data obtained from the study, SPSS (Statistical Package for Social Sciences) for Windows 20.0 program was used for the statistical analysis. Distribution of variables was controlled by using Kolmogorov Smirnov Test. During the evaluation of the study data, regarding the comparisons of descriptive statistical methods (frequency, rate, mean, and standard deviation) as well as quantitative data, Student $t$ test and Mann Whitney $U$ tests were used. Chi-square test was used regarding the comparison of the qualitative data. Paired sample $t$ test and Wilcoxon tests were used for repetitive measurements. The results obtained from the study were evaluated within $95 \%$ confidence intervals and at a significance level of $p<0.05$ level.

\section{Results}

The study was conducted on 62 patients with acute respiratory failure who were hospitalized in the intensive care unit of our clinic and had invasive mechanical ventilatory support for more than $48 \mathrm{~h}$. Eleven of these cases developing respiratory failure in the 1 st hour of extubation and 1 case operated for acute abdomen on the 12th hour of the study were excluded from the study. The remaining 50 patients in both groups who were followed-up with VM after a successful weaning for $1 \mathrm{~h}$ were included in the study. There was no significant difference between two groups regarding age, gender distribution and APACHE II scores $(p>0.05)$ (Table 1).

The study period was $48 \mathrm{~h}$ after extubation. Systolic blood pressure, peak heart rate, respiratory rate, $\mathrm{PaO}_{2}$ and $\mathrm{PaCO}_{2}$ and $\mathrm{pH}$ values were recorded and compared at certain time intervals.

When T-circuit was at the 30th minute in Group VM and Group NIV, there was no significant difference $(p>0.05)$
Table 1 Baseline characteristics of the patients.

\begin{tabular}{clll}
\hline & Group VM & Group NIV & $p$-value \\
\hline Age & $67.84 \pm 17.31$ & $71.88 \pm 11.00$ & 0.330 \\
Sex & & & \\
F & $15(60 \%)$ & $12(48 \%)$ & 0.395 \\
M & $10(40 \%)$ & $13(52 \%)$ & \\
APACHE II & $20.76 \pm 7.03$ & $19.54 \pm 4.46$ & 0.474 \\
\hline
\end{tabular}

between systolic blood pressure values in the 1st, 2 nd, 3 rd, 4th, 5th, 6th, 12th, 24th, 48th hours.

When T-circuit was at the 30th minute in Group VM and Group NIV, there was no significant difference $(p>0.05)$ between peak heart rate values in the $1 \mathrm{st}, 2 \mathrm{nd}$, 3rd, 4th, 5th, 6th, 12th, 24th, 48th hours. Group VM had significantly higher pulse rates $(p<0.05)$ than Group NIV in the 2 nd hour $(98.7 \pm 15.1 ; 90.3 \pm 13.6 ; p=0.045)$.

When T-circuit was at the 30th minute in Group VM and Group NIV, there was no significant difference $(p>0.05)$ between respiratory rate (RR) values in the $1 \mathrm{st}, 2 \mathrm{nd}, 3 \mathrm{rd}$, 4th, 5th, 6th, 12th, 24th, 48th hours.

When T-circuit was at the 30th minute in Group VM and Group NIV, there was no significant difference $(p>0.05)$ between $\mathrm{PCO}_{2}$ values in the 1st, 6th, 12th, 24th, 48th hours.

When T-circuit was at the 30th minute in Group VM and Group NIV, there was no significant difference $(p>0.05)$ between $\mathrm{PO}_{2}$ values in the 1st, 12th, 24th, 48th hours. Group VM had significantly lower $\mathrm{PO}_{2}$ values $(p<0.05)$ than Group NIV in the 6th hour $(90.2 \pm 25.6 ; 112 \pm 29.2 ; p=0.015)$.

Respiratory failure developed in 19 of the 25 patients (76\%) in Group VM, whereas it developed only in $3(12 \%)$ of the 25 patients in Group NIV after extubation. In group VM, 14 of the 19 patients (73\%) NIV support was initiated, 5 patients $(26 \%)$ were directly reintubated. Four $(80 \%)$ of the 5 patients who were directly reintubated were died after the $48 \mathrm{~h}$ study period, during their stay in ICU with progressive respiratory failure due to COPD + Pnemonia in one and with acute cerebral bleeding, malignancy, abdominal sepsis developed after colon perforation in the other three patients.

Respiratory failure developed after extubation in only 3 (12\%) of 25 patients of group followed with NIV and they were reintubated. Two (66\%) of these were died after the study period before weaning. The causes of deaths were again related to the extrapulmonary reasons (acute cerebrovascular occlusion and acute coronary syndrome).

NIV was provided in 14 patients (56\%) in Group VM developing respiratory failure during follow-up with venturi mask and they could be discharged from the hospital without any need of reintubation. In group VM patients who needed NIV support, a significant decrease was observed in $\mathrm{PO}_{2}$ value at the 6th-12th hours and a significant increase VM.

The use of NIV support decreased respiratory failure ratio after extubation by $64 \%$, and reintubation and mortality rate by $8 \%$. Comparing the two groups in terms of respiratory failure after extubation a significant difference was seen $(p<0.05)$. No significant difference was detected regarding reintubation and mortality ratios $(p>0.05)$ (Table 2$)$. 
Table 2 No significant difference was detected regarding reintubation and mortality ratios.

\begin{tabular}{lccc}
\hline & Group VM & Group NIV & $p$-value \\
\hline $\begin{array}{l}\text { Respiratory failure } \\
\text { after extubation }\end{array}$ & $19(76 \%)$ & $3(12 \%)$ & 0.000 \\
$\begin{array}{l}\text { Reintubation } \\
\text { Duration of intensive } \\
\quad \text { care unit stay }\end{array}$ & $5(20 \%)$ & $3(12 \%)$ & 0.702 \\
$\quad \begin{array}{lll}\text { Outcome } \\
\quad \text { Exit }\end{array}$ & $5.2 \pm 4.9$ & 0.000 \\
$\quad$ Alive & $4(16 \%)$ & $2(8 \%)$ & 0.304 \\
\hline
\end{tabular}

\section{Discussion}

Current routine clinical practice of the weaning process is to extubate the patients eligible for weaning criteria and follow-up the group who seem to be stabilized in terms of respiration with VM.

While this process is well tolerated by some patients and weaning process can easily be completed, during prolonged VM period, some patients may need respiratory support due to insufficiency of ventilation capacity, rapid superficial breathing, inability to protect airway, secretion collection and atelectasis formation in the advancing hours even though they seem to be stabile in the first hours of the process. ${ }^{4-7}$ To be insistent on VM follow-up for these groups of patients may cause the patient to lose the opportunity for NIV leading to the reintubation process with accompanying risks.

We performed our study on the patients who fulfilled the weaning criteria, kept respiratory and hemodynamic stability after $30 \mathrm{~min}$ T-piece trial and then extubated. We aimed to observe the effects of NIV support on respiratory failure development, duration of stay in the intensive care unit and mortality rates in this patient group who were allowable for follow-up with venturi mask, namely the patients for whom respiratory failure were not foreseen under normal conditions. We preferred to use NIV support continuously for $48 \mathrm{~h}$ in our patients. However, we also carried out a protocol based on care, feeding and short rest intervals considering patient comfort. When the patients with oronasal mask were observed to have nasal pressure, full-face mask alternative was used to prevent nasal injury. None of the patients suffered from complications such as gastric distension, regurgitation and vomiting and there was no need for sedation in any group.

Nava et al. investigated NIV use in patients fulfilling weaning criteria but at risk for respiratory failure after extubation also used a similar method (successive NIV applications in the first $48 \mathrm{~h}$ ). In this study, 97 patients were divided into two groups as standard medical treatment (VM) or NIV use. While 12 of 49 patients in control group were reintubated, 4 of 48 patients in NIV group were reintubated $(p=0.027)$. Hence, the use of NIV decreased reintubation by $16 \%$ and the risk of intensive care unit mortality by $10 \%$ $(p<0.01)$. Besides these, need for reintubation was found to be associated with a $60 \%$ increase in the risk of intensive care unit mortality $(p<0.01)$. When durations of stay in the intensive care unit of the patients with reintubation need were compared with the other patients, it was seen that it was statistically significantly longer $(28.3 \pm 29.5$ vs. $8.6 \pm 5.1)$. These researchers concluded that the inhibitory use of NIV decreased the requirement of reintubation in patient subgroups passing spontaneous breathing trials but having respiratory failure risk after extubation. ${ }^{5}$

Similar results were found in another study performed by Ferrer et al. ${ }^{6}$ In this study, like ours, NIV was used as an preventive treatment method for the patients who were successfully weaned after the T-piece trial, and compared to the control group who had venturi mask instead. As a result of the study performed on 162 patients, researchers found that the use of NIV decreased the incidence of respiratory failure after extubation considerably and intensive care unit mortality rate also decreased. However, they could not find a significant difference between 90 -day survival rates of the two groups.

We chose our study group from the patients in whom respiratory failure was not foreseen after extubation. If any deterioration during the follow-up period occurs; that is: respiratory rate above 25 breaths/ $\mathrm{min}, \mathrm{SO}_{2}: 90 \%$ and below; $\mathrm{PO}_{2}: 70 \mathrm{mmHg}$ and below; NIV applied to the patient under VM. If the respiratory rate above 35 breaths $/ \mathrm{min}, \mathrm{SO}_{2}: 90 \%$ and below; $\mathrm{PO}_{2}: 60 \mathrm{mmHg}$ and below or the hemodynamic parameters were impaired, the patients in both groups were directly intubated to have invasive mechanical ventilator support. NIV was provided in 14 patients (56\%) in Group VM developing respiratory failure during follow-up with venturi mask and these patients could be discharged from hospital without any need of reintubation.

In their study performed on 158 patients, Meduri et al. ${ }^{7}$ showed that NIV could be an effective method to treat respiratory failure after extubation and $65-70 \%$ of the patients whose reintubation was unavoidable could benefit from NIV. Thirty-nine of these patients were supported with NIV due to respiratory failure after extubation and an improvement was observed in arterial blood gas values of $88 \%$ of them. Therefore, the need for reintubation removed in $65 \%$ of these patients.

Problems originating from the cardiovascular system can be a hidden cause of weaning failure. Respiratory muscle pathology can be found in the patients with heart failure due to inspiratory muscles overload or generalized muscular atrophy and muscle weakness related to cardiac, cachexia or decrease in respiratory muscle blood flow. Respiratory muscle abnormality is an important pathology contributing to the development of respiratory failure in these patients. In the studies performed, it was shown that NIV support had beneficial effects on respiratory muscles in acute and chronic heart failure. In their studies, Lemaire et al. showed that there were direct increases in transmural pulmonary arterial occlusion pressure during T-piece application and this increase could be avoided with application of intrathoracic pressure with NIV support by decreasing preload and after load of the heart. Although none of our patients had acute heart failure, mean age of the groups were $67 \pm 17$ years in Group VM and $71 \pm 11$ years in Group NIV, that may mean some degree of cardiac dysfunction might be a contributing factor for their respiratory distress. So, we can say that favorable effects on cardiac functions might have also been a beneficial factor for pulmonary recovery in patients administered with NIV support. 
NIV support could be used carefully in patients developing respiratory failure after extubation but it should be taken into consideration that dangerous delays in reintubation during treatment of respiratory failure after extubation with NIV support could result in adverse outcomes for the patients. In their meta-analysis performed by reviewing the studies on this subject, Agarwal et al. concluded that it is suggested that protocols should be developed for NIV use in the patients at risk for developing respiratory failure after extubation. $^{8}$

In our study, we observed that provision of prophylactic NIV support for at least $48 \mathrm{~h}$ after weaning under optimal conditions in the patients who had invasive mechanical ventilatory support for more than $48 \mathrm{~h}$ due to acute respiratory failure and for whom respiratory failure were not foreseen after extubation decreased the duration of stay in the intensive care unit and risk for respiratory failure that could develop. Although the use of NIV is not suggested except the patients at high risk for extubation success; based on the results we obtained from our study, we consider that the prophylactic use of NIV can be beneficial.

\section{Conflicts of interest}

The authors declare no conflicts of interest.

\section{References}

1. Demaule A, Giraou E, Richard JC, et al. Increased use of noninvasive ventilation in French intensive care units. Intensive Care Med. 2006;32:1747-55.

2. Esteban A, Frutos-Vivar F, Ferguson ND, et al. Noninvasive positive-pressure ventilation for respiratory failure after extubation. N Engl J Med. 2004;350:2452-60.

3. Keenan SP, Powers C, McCormack DG, et al. Noninvasive positivepressure ventilation for postextubation respiratory distress: a randomized controlled trial. JAMA. 2002;287:3238-44.

4. Nava S, Ambrosino N, Clini E, et al. Noninvasive mechanical ventilation in the weaning of patients with respiratory failure due to chronic obstructive pulmonary disease. A randomized, controlled trial. Ann Intern Med. 1998;128:721-8.

5. Nava S, Gregoretti C, Fanfula F, et al. Noninvasive ventilation to prevent respiratory failure after extubation in high-risk patients. Crit Care Med. 2005;33:2465-70.

6. Ferrer M, Valencia M, Nicolas JM, et al. Early noninvasive ventilation averts extubation failure in patients at risk: a randomized trial. Am J Respir Crit Care Med. 2006;15:164-70.

7. Meduri GU, Turner RE, Abou-Shala N, et al. Noninvasive positive pressure ventilation via face mask. First-line intervention in patients with acute hypercapnic and hypoxemic respiratory failure. Chest. 1996;109:179-93.

8. Agarwal R, Aggarwal AN, Grupta D, et al. Role of noninvasive positive-pressure ventilation in postextubation respiratory failure: a meta-analysis. Respir Care. 2007;52:1472-9. 